succession, $(b)$ the structure viewed in the light of $(a)$. With regard to the first of these, the present state of our knowledge does not seem to warrant the sweeping generalizations made in this book. There is no doubt something to be said for an eventual simplification in the nomenclature and classification of the Dalradian schists as a whole, and probably this simplified nomenclature will be feasible first in the South-West Highlands; since, however, such a simplification inevitably carries with it a correlation, it should be applied even here with the utmost caution at the present day. Its adoption may lead, indeed, to the obscuring of important issues, as seems to have been the case here in dealing with the Cowal country ; Clough realized the difficulties in the interpretation of this region, as is manifest in his Cowal Memoir, but Gregory using his simplified classification has merely glossed them over; they are there none the less.

As might be expected from his earlier papers, Gregory has devoted considerable space to an attempt to establish his Lennoxian Series as distinct from the Dalradian; his evidence is very unconvincing, and seems, indeed, largely to be based upon an entire misconception regarding the metamorphic condition of his Loch Lomond Series. It is a great pity that he tries to force this succession upon the Pre-Cambrian rocks of other countries.

Gregory's views upon metamorphism generally are quite incomprehensible, no clue is given in the book to the facts upon which they are based, and they are so completely at variance with the results obtained by many present-day workers at home and abroad that they inspire no confidence. With regard to the second problem, that of structure, Gregory takes far too much in the Highlands at its face value: he has failed to realize that many of the structures shown in his sections (all too much exaggerated in the vertical scale) are merely superficial: they might all be obliterated, and the structural problem of the Dalradians would still remain.

G. L. E.

\title{
CORRESPONDENCE.
}

\section{SOME RECENT CONTRIBUTIONS TO THE PLEISTOCENE SUCCESSION IN ENGLAND.}

Sin,-My thanks are due to Mr. J. Reid Moir and to Professor P. G. H. Boswell for correspondence which has appeared in the Geological Magazine of February and March respectively, with reference to some notes published under the above title in January. The following brief replies may be made.

In the first place, perhaps I may remind Mr. Reid Moir that, if he wishes to apply the glacial sequence of the Alps to this country 
(in which I am in no haste to follow him), some difficulties seem likely to arise from regarding, as he does, if I am not mistaken, the first glacial episode as of pre-Cromer Forest Bed age and the last phase of the last glaciation as a distinctly late Palaeolithic event. The glacial series of Penck and Brückner has, in the course of years, been called upon to behave like a concertina in its relation to Palaeolithic man in this and other countries: at times it has been stretched to its utmost, at times it has suffered compression, trials almost beyond its elastic strength. I am not quite sure how Mr. Reid Moir proposes to regulate its length. So far as my references to the glacial sequence of East Anglia are concerned, I must attribute my information chiefly to Mr. Reid Moir himself, and to Professor Boswell (particularly to the latter's recent paper in the Proceedings of the Geologists' Association). I can claim no private store of information. In view of Professor Boswell's promised conspectus of the problem a little later in the year, and of Mr. Reid Moir's forthcoming monograph for the Field Museum of Chicago, it seems unprofitable to play further upon the scale of time until these two opera are published.

Secondly, I must confess that I was aware that Lower Acheulean implements were found, as Mr. Reid Moir reminds me, in the lower implementiferous beds of the Foxhall Road (Derby Road) section, and that they are as yet undiscovered in a similar position at Hoxne. By a verbal slip I seem to have suggested that they have, in fact, been found in that position at Hoxne, where every one expects them to occur, and I accept with thanks Mr. Reid Moir's correction. Hope was father to the thought. As he himself notes, the correction is one of precision, but it in no way affects the argument, which his own researches at Derby Road confirm.

Thirdly, with regard to Professor Boswell's amendment of a condensed table which I included in my notes (GEol. Mag., January, 1932, 15), I suspect him of keeping, or finding, a glacial oscillation up his sleeve, which now emerges as the twofold Lower and Upper Purple Boulder Clay of Yorkshire. In his paper, to which I am entirely indebted for my information, there seems to be not two but one Purple Boulder Clay. Its twofold nature allows the Hessle Boulder Clay to take its rightful place as the contemporary of the Brown Boulder Clay of Hunstanton, the Upper Purple Boulder Clay becoming the equivalent in Yorkshire of the Upper Chalky Boulder Clay (or Drift). The rest of the table on p. 15 remains unchanged. It seems to follow that the Hessle Boulder Clay is, in fact, the Newer Drift.

K. S. SANDFORD.

UnIVERSTTY MUSEUM, OXFORD. 